\title{
Adult outcomes of youths who have spent time in a judicial treatment institution in the Netherlands
}

\author{
Janna Verbruggen \\ Verbruggenj@cardiff.ac.uk \\ Victor van der Geest
}

V.vander.geest@vu.nl

Catrien Bijleveld

Cbijleveld@nscr.nl
Cardiff University, UK

VU University Amsterdam \& Netherlands Institute for the Study of Crime and Law Enforcement (NSCR), the Netherlands

Netherlands Institute for the Study of Crime and Law Enforcement (NSCR) \& VU University Amsterdam, the Netherlands

(Received April 2017 Revised December 2017)

http://dx.doi.org/10.14301/llcs.v9i1.461

\section{Abstract}

Youths who have spent time in residential care may experience difficulties when making the transition to adulthood. This study examines adult outcomes of youths $(\mathrm{N}=251)$ who spent time in a Dutch judicial treatment institution. Moreover, the study investigates to what extent background characteristics and patterns in adult criminal behaviour are related to outcomes in adulthood. The study uses data from the 17up study, a longitudinal study following institutionalised youths into adulthood. Information on background characteristics is available from the youths' treatment files. Outcomes in a variety of life domains, including the domains of housing, employment, family formation and health, have been assessed at a follow-up interview with respondents when they were, on average, 34 years old. Official data on criminal behaviour is used to reconstruct respondents' criminal careers. The findings show that many young people who were placed in a judicial treatment institution during their youth experience difficulties in conventional life domains in adulthood, in particular in the areas of employment, mental health, and alcohol and drug abuse. Furthermore, results from a series of regression analyses and nonlinear canonical correlation analyses suggest that in general, those with chronic involvement in criminal behaviour are more likely to experience problems in multiple adult life domains. Most background characteristics are unrelated to adult outcomes. Therefore, the findings indicate that among youths with a history of institutionalisation, negative outcomes in adulthood are not so much predicted by childhood risk factors, but more so by criminal involvement in adulthood.

\section{Keywords}

Adult outcomes; judicial treatment institution; residential care; offending trajectories 


\section{Introduction}

Youths who have spent time in residential care are at risk of experiencing difficulties when making the transition to adulthood, resulting in adverse outcomes in a variety of adult life domains. In the Netherlands, until recently, youths who displayed serious behavioural problems and/or delinquent behaviour could be placed in a specific type of residential care: a judicial treatment institution for juveniles. It is well documented that young people who have been placed in out-of-home care are at risk of experiencing negative outcomes in several domains, including in the areas of education, employment, wellbeing and mental health, and contact with the criminal justice system (e.g. Collins, 2001; Courtney \& Dworsky, 2006). Looking in particular at outcomes of youths who have spent time in an institution, research suggests that institutionalised youths face difficulties in conventional life domains. For example, employment rates after institutionalisation are generally low and youths often have financial problems (e.g. Boendermaker, 1998; Harder, Knorth \& Kalverboer, 2011; Van der Molen et al., 2013). A substantial proportion of previously institutionalised girls become mothers at a young age (Hamerlynck, 2008; Van der Molen et al., 2013). In addition, mental health problems are common, as is use of (inpatient) mental health treatment (e.g. Abram et al., 2015; Boendermaker, 1998; Ståhlberg et al., 2017; Van der Molen et al., 2013; Vinnerljung and Sallnäs, 2008). Furthermore, many previously institutionalised youths struggle with problematic alcohol and drug use (e.g. Harder et al., 2011; Welty et al., 2016). Finally, rates of criminal behaviour are high (e.g. Ståhlberg et al., 2017). For example, research by Wartna, el Harbachi and Van der Laan (2005) found that $32 \%$ of youths had been in contact with the criminal justice system one year after leaving an institution. This figure rose to $68 \%$ over a period of seven years.

Research indicates that outcomes for institutionalised youths are significantly worse compared to youths who were not institutionalised. To illustrate, those who experienced juvenile incarceration are less likely to graduate from high school (Aizer \& Doyle, 2015). Research by Davies and Tanner (2003) showed that boys and girls who spent time incarcerated had worse employment outcomes compared to young people who did not experience incarceration. Furthermore, Lanctôt, Cernkovich and Giordano (2007) demonstrated that, compared to youths who had not experienced institutionalisation, boys and girls who had been institutionalised experienced more difficulties in young adulthood, in terms of socioeconomic disadvantage, instability in the domains of work and relationships, and increased levels of depressive symptoms. In addition, a study by Vinnerljung and Sallnäs (2008) found that youths placed in an institution due to behaviour problems often experienced difficulties in young adulthood, including in the domains of crime, education and employment. Moreover, youths placed in an institution were more likely than youths placed in foster care to have low educational attainment, to receive substantial social assistance, and to experience hospitalisation for mental health problems in young adulthood. Finally, Gilman, Hill and Hawkins (2015) used a propensity score matching approach to compare youths who experienced incarceration during adolescence to youths who did not. The study demonstrated that those youths who experienced institutionalisation in adolescence were, compared to youths who were not institutionalised, more likely to have alcohol abuse problems, to receive public assistance, and to experience incarceration between ages 27 and 33, whilst they were not more likely to experience depression, anxiety or drug abuse.

However, most existing studies focused on small samples and/or have followed youths for a short period after leaving an institution (but see Gilman et al., 2015; Lanctôt et al., 2007). It is important to examine the long-term outcomes of youth who have spent time in an institution, as it might take them a while to establish themselves as adults. Moreover, most 
available research is carried out in the USA. One of the exceptions is an earlier study from the Netherlands that examined adult life adjustment of previously institutionalised youths who were followed up to an average age of 34 (Verbruggen, Van der Geest \& Blokland, 2016). Using the same sample as in the current study, the Verbruggen et al. (2016) research used a composite scale of adult life adjustment to determine how well previously institutionalised youths were adjusted to adult life domains. Findings indicated that institutionalised youths experienced problems in several conventional life domains. Moreover, when looking at the extent to which patterns in adult criminal behaviour were related to adult life adjustment, the results showed that those respondents with chronic involvement in offending had the lowest scores on the adult life adjustment scale.

The current study aims to build upon the study by Verbruggen et al. (2016), by firstly, providing a more detailed examination of adult outcomes of institutionalised youths by investigating life domains separately rather than looking at a composite measure of adult life adjustment, and secondly, by examining to which kind of factors the generally poorer adult outcomes of institutionalised youths are attributable. Although research generally points to negative outcomes among care leavers, there is debate about the precise reasons for these adverse outcomes. On the one hand, it may be argued that poor outcomes of institutionalised youths are due to pre-existing vulnerabilities. For example, children who are placed in an institution tend to come from families that experience a multitude of problems, and have often experienced childhood victimisation, including neglect, physical abuse and sexual abuse (Allroggen, Rau, Ohlert \& Fegert, 2017; Greger, Myhre, Lydersen \& Jozefiak, 2015; Van Vugt, Lanctôt, Paquette, Collin-Vézina \& Lemieux, 2014). Furthermore, these youths often display serious behaviour problems and may suffer from mental health problems (e.g. Colins et al., 2010; Fazel, Doll \& Långström, 2008; Tarren-Sweeney, 2008). These relatively stable individual and background factors contributed to their placement in an institution in the first place, and are assumed to put them at risk of longer term negative outcomes as well (e.g. Chung, Little \& Steinberg, 2005; Gottfredson \& Hirschi, 1990).

On the other hand, those taking a life-course perspective state that events that happen at different points in the life course could influence the likelihood of successful adaptation to adult life domains. The concept of cumulative disadvantage in particular is useful in explaining the generally poor adult outcomes of institutionalised youths (Sampson \& Laub, 1997). Although placement in an institution is aimed at offering treatment to youths who display serious behavioural problems, and could therefore have positive effects on youths' later societal adaptation, the experience of institutionalisation could also have unintended negative effects, as it weakens bonds to conventional society, especially when youths spend a long time in an institution. For example, when entering an institution, they may de-enrol from education and come primarily into contact with other youths with vulnerable backgrounds and problematic behaviour. When youths leave an institution, the combination of limited to non-existent aftercare and labelling effects due to the stigma attached to official intervention (e.g. Becker, 1963; Bernburg \& Krohn, 2003; Osgood, Foster, Flanagan \& Ruth, 2005) could lead to difficulties in areas such as housing, education and employment. The period after institutionalisation is therefore a critical period, in which youths are at risk of (continued) involvement in criminal behaviour and contact with the criminal justice system. Such (re-) involvement additionally decreases the likelihood of successful outcomes in conventional adult life domains as offending, and especially chronic offending and formal sanctions, are associated with reduced likelihood and quality of employment (Moffitt, Caspi, Harrington \& Milne, 2002; Nilsson \& Estrada, 2009), obstacles in family formation (Nilsson \& Estrada, 2009), adverse health outcomes (Piquero, Daigle, Gibson, Piquero \& 
Tibbetts, 2007), alcohol abuse (Moffitt et al., 2002), drug use (Piquero et al., 2007), further criminal justice involvement (Bernburg \& Krohn, 2003; Moffitt et al., 2002), and lower life success in general (Farrington et al., 2006; Piquero, Farrington, Nagin \& Moffitt, 2010).

In addition to describing the long-term adult outcomes of youths who spent time in a judicial treatment institution, this study will also examine the role of individual and background factors and adult criminal behaviour in explaining outcomes of institutionalised youths. By doing so, the current study builds upon previous research in this area, which generally follows institutionalised youths over relatively short periods, and is predominantly carried out in the USA. Following the previous literature and the theoretical framework discussed above, the three research questions central to this study are:

1. What are the outcomes of youths who have spent time in a judicial treatment institution in the domains of accommodation, employment, relationships, parenthood, health, and criminal behaviour?

2. What is the relationship between background characteristics and adult outcomes?

3. What is the relationship between criminal behaviour and adult outcomes?

\section{Methods}

\section{Sample}

This research uses data from the 17up study, a longitudinal study following institutionalised youths well into adulthood. ${ }^{1}$ The original sample of the 17up study consisted of 270 boys and 270 girls who were institutionalised in a Dutch judicial treatment institution for juveniles in the 1980-90s. The boys were discharged from the institution between 1989 and 1996, the girls between 1990 and 1999. Although at the time youths could be institutionalised in a treatment institution based on a criminal law measure or a civil law measure, all boys and girls in the sample were characterised by serious problem behaviour. All youths received treatment during their stay in the institution, which was aimed at reducing the young person's problematic and delinquent behaviour, as well as providing them education (for more information about the 17 up study and its sample, see Van der Geest, 2011, chapters 1 and 2; Verbruggen, 2014, chapter 1).

Between July 2010 and January 2012, we approached members of the original sample for a follow-up interview. A total of 41 individuals could not be approached, due to death $(\mathrm{N}=22)$, emigration $(\mathrm{N}=14)$, or because they were living in psychiatric or forensic institutions that refused to cooperate with the study $(\mathrm{N}=5)$. Of the 499 men and women we were able to approach, 251 agreed to an interview, resulting in a $50.3 \%$ response rate. Non-response analysis in which responders and non-responders were compared on a range of background and current characteristics revealed that the subsample is generally representative of the original sample (for more information, see Van der Geest, Bijleveld \& Verbruggen, 2013; Verbruggen et al., 2016).

Most interviews were conducted at the respondent's home, but occasionally in other places such as cafes. Interviews were conducted by trained interviewers and lasted 1.5 hours on average. The average age of the respondents at the time of the interview was 36.8 for men $(S D=2.4)$ and 32.9 for women $(S D=2.5)$. On average, respondents were interviewed 17.7 years after they had left the institution $(S D=2.8)$.

\section{Measures}

\section{Background characteristics}

Background characteristics of the youths had previously been extracted from their treatment files, which were constructed during their stay in the institution. These treatment files comprise a variety of reports, for example from psychologists, psychiatrists, social workers and pedagogical staff working with the groups in the institution, and contain information about the young person's background, family of origin, problem behaviour and mental health problems. Using this information, the following variables were constructed. Gender ( $0=$ male, $1=$ female); problems in the family of origin (sum of whether there was alcohol abuse, drug abuse, a parent with psychopathology, family members with a criminal history or 
unemployment in the family), childhood victimisation (sum of whether respondents experienced neglect, physical abuse or sexual abuse), psychopathology (for example, depression, conduct disorder, or ADHD (yes/no)), and aggression (yes/no). The files also provide information about the start and end date of the period of institutionalisation, length of institutionalisation, and whether a young person was institutionalised based on a civil law or criminal law measure. Finally, a variable representing whether respondents completed any education was created (yes/no), based on answers to closed-ended questions in the interviews that asked whether respondents completed any education during or after their time in the institution.

\section{Criminal behaviour}

In earlier work on the 17up sample, groupbased trajectory modelling had been used to estimate offending trajectories from ages 18 to 34 (Verbruggen et al., 2016), and these offending trajectories are used in the current study as well. As discussed in Verbruggen et al. (2016), officially registered data on convictions, retrieved from the judicial documentation abstracts of the Netherlands Ministry of Security and Justice, was used. Group-based trajectory modelling (Nagin, 1999; Nagin, 2005) is a technique that identifies clusters of individuals following developmental pathways that are relatively similar in both the level and shape of offending with age (Nagin, 1999). The procedure for estimating offending trajectories is described in more detail in Verbruggen et al. (2016). The analysis had revealed four distinct offender groups in the sample. The largest group in the sample (59\% of the sample) can be classified as low-rate desisters. This group consists of individuals who have virtually no convictions in adulthood. The second group is a fairly small group of high-rate desisters (11.6\% of the sample). This group mainly shows offending behaviour in early adulthood. On average, their conviction rate peaks at age 19, and then decreases quickly. By the age of 23 this group has desisted from offending according to the official conviction data. Group 3 is a low-rate chronic offender group, consisting of about $20 \%$ of the total sample. These offenders are characterised by a chronic offending pattern between ages 18 and 34, although their conviction rate is declining with age. Finally, a small high-rate chronic offender group (9.2\%) is composed of individuals who show a considerably higher conviction rate throughout adulthood than the other three groups. Their offending behaviour peaks around age 23 and slowly decreases thereafter. However, by the age of 34 , their rate of offending is still quite a bit higher compared to the other groups (see figure 1). The officially registered conviction data were also used to construct a variable that indicates whether respondents were convicted between ages 12 and 17.

\section{Adult outcomes}

During the interview, structured, semistructured and open-ended questions were posed to assess outcomes in a variety of adult life domains in the year preceding the interview. We investigate outcomes in a variety of conventional life domains, namely accommodation, employment, intimate relationships, parenthood, (mental) health, depression, alcohol abuse, and drug abuse. Variables were coded in the following way.

A variable for accommodation was constructed, which indicated whether respondents lived in a house at the time of the interview, as opposed to living in an institution or detention centre, staying at relatives or friends, or being homeless. The employment variable measured whether respondents were formally employed (i.e. employment for which taxes are paid) at the time of the interview. Employed respondents completed an employment quality questionnaire, derived from the Rochester Youth Development Study. The scale consisted of nine items that are rated on a 5 -point scale $(1=$ totally disagree through 5 = totally agree), and reliability of the scale in this study was good (Cronbach's alpha $=0.85$ ). 


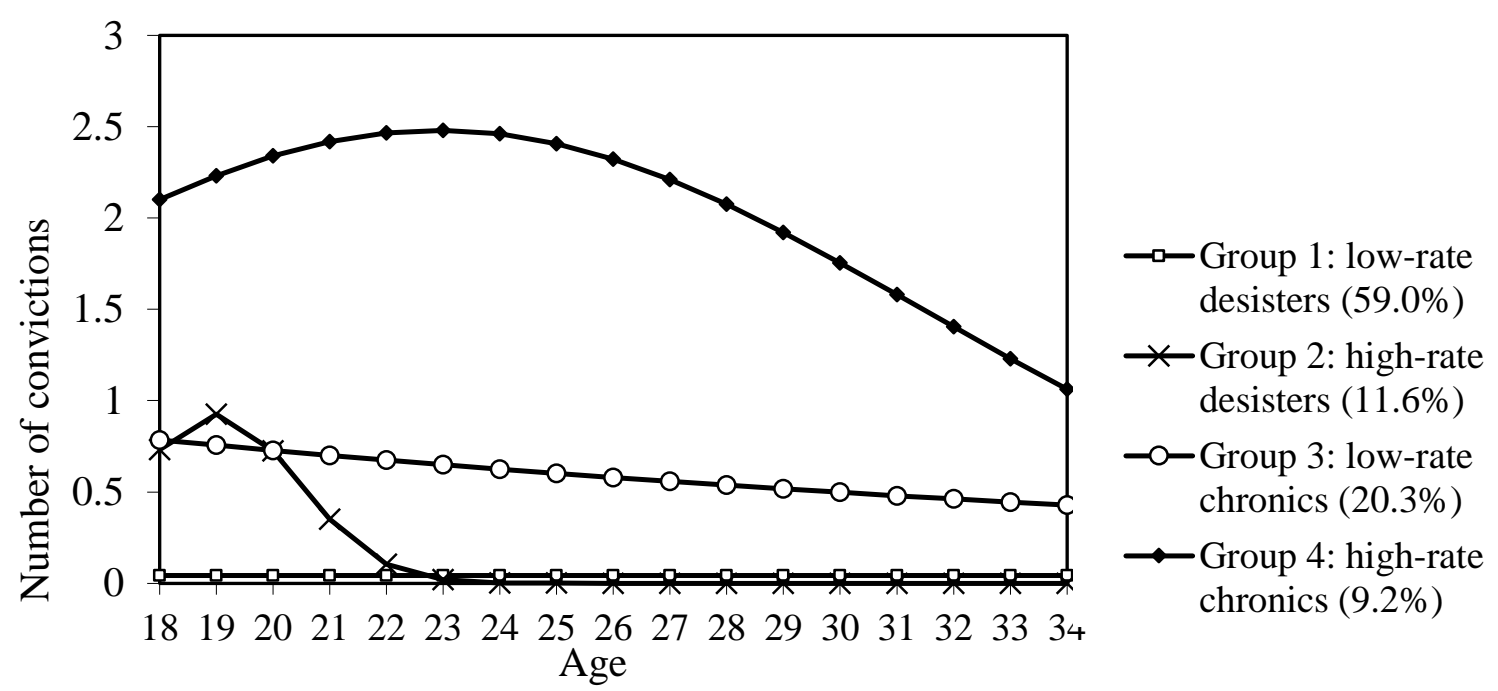

Figure 1. Conviction trajectories from ages 18 to 34

Using this information, an average measure of employment quality was constructed. The intimate relationships variable was based on whether respondents reported that they were in a romantic relationship at the time of the interview. Those who were in a relationship filled in a questionnaire consisting of ten items rated on a 4-point scale $(1=$ never through $4=$ often), derived from the Rochester Youth Development Study, based on which an average measure of relationship quality was created. Reliability of the scale in this study was good (Cronbach's alpha $=0.85$ ). The variable parenthood indicated whether respondents have at least one child at the time of the interview. In addition, for those respondents who reported that they were parents, another variable was created to measure whether respondents were in regular contact (defined as daily or weekly contact) with their child(ren). There was also information about whether respondents financially contributed to raising their child(ren).

Questions derived from the Dutch Health Monitor (GGD, 2005) were used to ask respondents whether they had had contact with several healthcare professionals in the past 12 months. A contact with mental health services variable was constructed, representing whether respondents visited at least one mental health professional (i.e. mental health service, psychologist, psychiatrist, or addiction care service). Similarly, a variable contact with other health services was created, indicating whether respondents visited a medical specialist, company doctor, or A \& E. ${ }^{2}$ Although contact with health services could be of a preventative nature, qualitative data from the semistructured interviews suggest that the vast majority of respondents who have been in contact with health services suffer from a range of (serious) physical and mental health issues, and we therefore see contact with health services as an indicator of poor health. In addition, depression was measured using 19 items from the Center for Epidemiological Studies Scale for Depression (CES-D) (Radloff, 1977). Questions were answered on a 4-point scale ( $0=$ rarely or never, $1=$ sometimes, $2=o f t e n$, $3=$ most of the time or always) and values were summed. A respondent was coded as meeting the criteria for depression when their score was equal to or higher than the cut-off point of 16 . A mean score across items per participant was also calculated. Reliability of the scale in this study was excellent (Cronbach's alpha $=0.92$ ).

The variables for alcohol abuse and drug abuse were constructed in a similar way and were based on items derived from the Composite International Diagnostic Interview 
(CIDI). These items asked respondents whether they had used alcohol and (soft and hard) drugs in the past 12 months, and whether they had experienced difficulties in conventional life domains as a consequence of their alcohol or drug use. Following the DSM-IV-TR criteria for alcohol abuse and drug abuse, variables were created that indicated whether subjects met the criteria for alcohol abuse or drug abuse. ${ }^{3}$

\section{Analysis}

Descriptive statistics were used to describe respondents' background characteristics and outcomes on a variety of life domains. Furthermore, regression analysis was used to examine the relationship between background characteristics, criminal behaviour and different adult outcomes. In total, 13 regression analyses were conducted. Binary logistic regression analysis was used for dichotomous outcome variables (accommodation, employment, intimate relationships, parenthood, regular contact with child(ren), financially contributing to child(ren), contact with mental health services, contact with other health services, depression, alcohol abuse, and drug abuse) and linear regression analysis was used for continuous outcome variables (employment quality and relationship quality). Background characteristics and criminal trajectory group membership were included in all the models.

Next, nonlinear canonical correlation analysis ${ }^{4}$ was used to explore the association between patterns in adult criminal behaviour and various adult outcomes. This technique allows exploration of whether the crime trajectory groups can be characterised in terms of (combinations of) multiple adult outcomes, or profiles. Rather than predicting a single adult outcome, this exploratory technique allows positioning of respondents in a multidimensional solution in such a way that respondents are placed close to the adult outcomes they achieved. Because it is not possible to accommodate all combinations of adult outcomes perfectly for all respondents, the technique arrives at a compromise solution. This means, more technically, that in our study the nonlinear canonical correlation analysis attempts to optimise the association between a first set of variables that contains trajectory group membership (i.e. whether a respondent is allocated to trajectory group 1, 2, 3 or 4), and a second set that contains various outcome variables: accommodation, being employed, being in an intimate relationship, having regular contact with child(ren), contributing financially to child(ren), contact with mental health services, contact with other health services, depression, alcohol abuse, and drug abuse. For this purpose, we estimated a two-dimensional solution, in which both respondents and rescaled categories are positioned. In the solution, respondents (who are assigned positions in the solution called 'object scores') and rescaled categories (who are assigned positions in the solution '[projected] category centroids') are positioned such that respondents can be characterised in terms of certain patterns of adult outcomes. Respondents with similar scores on the variables are placed close together. The technique therefore enabled us to inspect what (groups of) respondents can be characterised by what set or profile of adult outcomes. Adult outcome categories shared by many are placed centrally, because they are not characteristic for certain (subgroups) of respondents. Likewise, centrally placed respondents cannot be characterised in terms of certain (combinations of) adult outcome categories. Adult outcomes that are placed away from the centre indicate more typical subgroups characterised by particular outcomes. A fit measure is indicative of how successful the technique has been. Fit values under 0.5 are generally considered to be unsatisfactory. For more information, see Gifi (1990).

\section{Results}

\section{Background characteristics}

The youths in the sample were on average 15 years old $(S D=1.6)$ when they were placed in the institution, and on average 16 years old $(S D=1.4)$ when they left. Youths spent an average of 17 months $(S D=11.8)$ in the institution. The majority of the boys and girls 
were placed in the institution based on a civil law measure (93.6\%) (see table 1).

The institutionalised youths had problematic backgrounds. ${ }^{5}$ Two-thirds of the sample had experienced at least one problem in their family of origin (i.e. alcohol abuse, substance abuse, a parent with psychopathology, family members with a criminal history or unemployment). Furthermore, almost $85 \%$ of these young people had experienced at least one form of childhood victimisation (i.e. neglect, physical abuse or sexual abuse). Finally, psychological problems were common. Almost two in three boys and girls (67.3\%) had been diagnosed with some form of psychopathology (for example, depression, conduct disorder, or ADHD).

Although one of the aims of the institution was to provide education to young people, not all completed an education whilst in the institution, probably due to a short length of stay. Although some managed to return to education and get at least one qualification after their stay in the institution, 90 respondents (35.9\%) reported in the interview that they had no qualifications.
With regard to their criminal behaviour, twothirds of the youths had been convicted before the age of 18 . More boys than girls were convicted (81.4 and $52.6 \%$ respectively). A similar number of respondents were convicted at least once in adulthood.

\section{Adult outcomes}

Descriptive statistics of outcomes in a variety of life domains can be found in table 2 . The vast majority of respondents (86.1\%) were living in regular accommodation (i.e. a house/flat) at the time of the interview. Among those not living in regular accommodation, 18 were incarcerated or institutionalised, 15 were staying with relatives or friends, and two were homeless.

Less than half of the sample $(44.9 \%)$ was employed at the time of the interview. However, among those who were employed, the average level of self-reported employment quality was high ( $M=4.04, S D=0.75$, on a 5 -point scale). This seems to indicate that, although employment participation in the sample is relatively low, those who do manage to make the transition to the labour market do not necessarily end up in low-quality jobs, but are generally satisfied with their jobs.

Table 1. Background characteristics of youths who have spent time in a judicial treatment institution ( $\mathrm{N}=\mathbf{2 5 1})$

\begin{tabular}{|c|c|c|c|c|}
\hline & $\mathbf{n}$ & $\%$ & Mean & SD \\
\hline $\begin{array}{l}\text { Institutionalised on civil law } \\
\text { measure }\end{array}$ & 235 & 93.6 & & \\
\hline Age at start institutionalisation & & & 15.5 & 1.6 \\
\hline Age at end institutionalisation & & & 16.9 & 1.4 \\
\hline $\begin{array}{l}\text { Length of institutionalisation (in } \\
\text { months) }\end{array}$ & & & 17.1 & 11.8 \\
\hline $\begin{array}{l}\text { Problems in the family of origin } \\
\text { (any) }\end{array}$ & 158 & 62.9 & & \\
\hline \# Problems in the family & & & 1.18 & 1.20 \\
\hline Victimisation (any) & 212 & 84.5 & & \\
\hline \# Victimisation & & & 1.35 & 0.85 \\
\hline Psychopathology & 169 & 67.3 & & \\
\hline Not completed education & 90 & 35.9 & & \\
\hline Convicted before age 18 & 166 & 66.1 & & \\
\hline Convicted age $18+$ & 160 & 63.7 & & \\
\hline
\end{tabular}


Almost two-thirds of the respondents (62.9\%) had a stable relationship at the time of the interview. Those who were in a relationship generally rated their relationship as being of good to high quality $(M=3.37, S D=0.46$, on a 4point scale). The majority of respondents $(78.8 \%$ of women and $55.9 \%$ of men) had children. Women had their first child at a relatively young age $(M=21.6, S D=4.1)$, whereas men were, on average, older when they became a parent $(M=28.1, S D=4.9)$. Among parents, the majority of men and women had regular contact (i.e. daily or weekly) with their child(ren), and contributed financially to raising the child(ren).

Furthermore, respondents reported whether they had had contact with health professionals in the year prior to the interview. More than one in three respondents (36.5\%) had gone to see a mental health professional (mental health service, psychologist, psychiatrist, or addiction care service), and the average number of mental health professionals visited in this group was 2.25 ( $S D=1.06)$. Moreover, half of the respondents $(49.0 \%)$ reported that they had visited at least one other healthcare professional (medical specialist, company doctor, or an A\&E) in the past 12 months. Among those who visited at least one other healthcare professional, the average number of different professionals visited was 1.49 $(S D=0.58)$. In addition, almost one in four respondents met the criteria for depression as measured with the CES-D. Other psychological and psychiatric disorders commonly reported in the interviews were borderline personality disorder (13.2\%), schizophrenia (6.4\%), and post-traumatic stress disorder (5.2\%).

Moreover, a substantial part of the respondents reported problematic substance use. One-third of the respondents (33.2\%) met the criteria for alcohol abuse, and almost $30 \%$ of respondents met the criteria for drug abuse, mostly marijuana, but also (problematic use of) hard drugs. In the past year, $14 \%$ of respondents had been in touch with an addiction care service (table 2 ).

\section{The relationship between background factors, offending patterns, and outcomes in adult life domains}

A series of regression analyses were conducted to investigate the relationship between background factors, offending trajectories, and a total of 13 different outcomes in adulthood (table 3). Note that table 3 contains the results of 11 regression analyses, as models in which none of the variables of interest were significantly related to the outcome variable are not displayed.

With regard to the life domain of accommodation, the results showed that the two chronic offender groups (3 and 4) were significantly less likely to live in a satisfactory accommodation situation at the time of the interview, meaning they were more likely to be either incarcerated, institutionalised, homeless, or staying with relatives or friends. Interestingly, childhood victimisation was also associated with a reduced likelihood of living in regular accommodation in adulthood.

Furthermore, the high-rate chronic offender group (4) was less likely to be employed at the time of the interview. Moreover, those who did not complete an education during or after institutionalisation were significantly less likely to be employed. Perhaps surprising is that those who were convicted before age 18 and those in the high-rate desister group (2) were more likely to be employed, although the effect for the high-rate desister group was marginally significant. When looking at the average level of employment quality among those who were employed, the findings indicated that the lowrate chronic offenders appeared to be employed in jobs of significantly lower quality, whereas none of the other variables were significantly related to the level of employment quality. Taken together, these findings indicate that chronic offenders were less likely to be employed, as well as more likely to be employed in low-quality jobs. In addition, not finishing school was associated with decreased job prospects. 
Table 2. Outcomes in adult life domains of youths who have spent time in a judicial treatment institution ( $\mathrm{N}=\mathbf{2 5 1}$ )

\begin{tabular}{|c|c|c|c|c|c|c|}
\hline Domain & $\mathbf{N}$ (total)* & $\mathbf{n}$ & $\%$ & Mean & SD & Min-Max \\
\hline Accommodation (regular) & 251 & 216 & 86.1 & & & \\
\hline Employed & 234 & 105 & 44.9 & & & \\
\hline Employment quality & 102 & & & 4.04 & 0.75 & $1-5$ \\
\hline In intimate relationship & 248 & 156 & 62.9 & & & \\
\hline Relationship quality & 137 & & & 3.37 & 0.46 & $1-4$ \\
\hline Parent & 250 & 170 & 68.0 & & & \\
\hline Regular contact with child(ren) & 163 & 137 & 84.0 & & & \\
\hline $\begin{array}{l}\text { Contributing financially to } \\
\text { child(ren) }\end{array}$ & 166 & 136 & 81.9 & & & \\
\hline \multicolumn{7}{|l|}{$\begin{array}{l}\text { Contact with health } \\
\text { professionals: }\end{array}$} \\
\hline Medical specialist & 222 & 105 & 47.3 & & & \\
\hline Company doctor & 209 & 29 & 13.9 & & & \\
\hline$A \& E$ & 217 & 49 & 22.6 & & & \\
\hline Mental health service & 216 & 53 & 24.5 & & & \\
\hline Psychologist & 216 & 55 & 25.5 & & & \\
\hline Psychiatrist & 217 & 44 & 20.3 & & & \\
\hline Addiction care service & 214 & 30 & 14.0 & & & \\
\hline $\begin{array}{l}\text { Contact with mental health } \\
\text { services (at least } 1 \text { visit) }\end{array}$ & 222 & 81 & 36.5 & & & \\
\hline $\begin{array}{l}\text { Contact with mental health } \\
\text { services (sum \# professionals } \\
\text { visited) }\end{array}$ & 222 & & & 2.25 & 1.06 & $1-4$ \\
\hline $\begin{array}{l}\text { Contact with other health } \\
\text { services (at least } 1 \text { visit) }\end{array}$ & 223 & 123 & 49.0 & & & \\
\hline $\begin{array}{l}\text { Contact with other health } \\
\text { services (sum \# professionals } \\
\text { visited) }\end{array}$ & 223 & & & 1.49 & 0.58 & $1-3$ \\
\hline Depression & 226 & 53 & 23.5 & & & \\
\hline Depression (average score) & 226 & & & 0.52 & 0.52 & $0-3$ \\
\hline Alcohol abuse & 226 & 75 & 33.2 & & & \\
\hline Drug abuse & 223 & 64 & 28.7 & & & \\
\hline
\end{tabular}

* Note: The $\mathrm{N}$ (total) is smaller than the total sample size of $\mathrm{N}=251$ when respondents have not provided data on particular life domains, or when outcomes were not applicable (for example, questions about contact with children were not answered by respondents who did not have children). 
Next, the regression models showed that offending patterns in adulthood were not significantly associated with the likelihood of being in a relationship or with the likelihood of having children. However, those respondents who were convicted before age 18 were less likely to be in a relationship at the time of the interview. Results for the regression analysis looking at relationship quality are not displayed in table 3 , as none of the variables were significantly associated with the average level of relationship quality.

Women were more likely to have children compared to men. Interestingly, although offending patterns in adulthood were not significantly related to the likelihood of having children, they were associated with the likelihood of being involved in the lives of the child(ren). Among those who had children, both chronic offender groups (groups 3 and 4) were significantly less likely to have regular contact with their child(ren), as well as to be financially contributing to the upbringing of the child(ren). In addition, those who had been diagnosed with a mental health disorder in adolescence were less likely to be in regular contact with their children, and those who spent a longer time in the judicial treatment institution were less likely to financially contribute to their child(ren), although both these effects were marginally significant.

The findings of the regression analyses examining the relationship between background factors, offending patterns and different healthrelated outcomes in adulthood indicated that those engaging in adult criminal behaviour generally showed poorer outcomes in the domains of mental health and drug abuse. The high-rate chronic offenders had a significantly higher likelihood of being in contact with mental health services. In addition, those who did not complete an education and those who experienced more problems in their family of origin were more likely to visit a mental health professional. Furthermore, those in the two chronic offender groups were significantly more likely to meet the criteria for drug abuse, as were those who displayed aggressive behaviour in adolescence. Moreover, the high-rate desister group was significantly less likely to meet the criteria for alcohol abuse compared to the low-rate desister group, and men were more likely than women to report alcohol abuse. Depression was predicted by psychopathology diagnosed during adolescence only, whilst other background factors and patterns in offending were not significantly related to the likelihood of meeting the criteria for clinical depression. Finally, the results for the regression analysis looking at contact with other health services are not displayed in table 3 , as neither offending patters in adulthood, nor background characteristics were significantly associated with this outcome variable.

\section{The association between adult outcomes and trajectory group membership classification}

Next, we performed a nonlinear canonical correlation analysis to investigate the multivariate association between criminal career patterns and adult life outcomes. Including all trajectory groups in the first set in the analysis, and all adult life outcomes in the second set, the analysis converged to a first solution with high-rate chronics positioned at the high end of both the first and the second dimension. Although high-rate chronics were set relatively far apart from all other trajectory groups, category centroids were placed centrally and the offender groups - the highrate chronic group in particular - could not be characterised in terms of outcome characteristics. It is likely that the small subsample size $(9.2 \%)$ further limited the ability to identify a clear profile of adult outcomes associated with the high-rate chronic offending group. To explore subgroup characterisation in terms of adult outcomes, we therefore excluded high-rate chronics from the subsequent analysis. 
Running the analysis for the remaining three subgroups, the solution contained categories that were placed more or less in line with the dimensions, such as substance abuse, which is characteristic of those with elevated scores on the first dimension, and employment, which is characteristic of those with higher scores on the second dimension. This solution had a fit of 1.687 , which is quite satisfactory. The fit equals the sum of the eigenvalues: the eigenvalue of the first dimension was 0.891 , and the second dimension had an eigenvalue of 0.796 . Figure 2 shows the object scores by group. These scores reflect the positions in the solution where respondents were assigned on the basis of similarity of outcome characteristics.

To interpret the dimensions, we depict the category centroids in figure 3 . For ease of examination, we leave out the category centroids of adult outcomes with only centrally placed categories, such as contact with health services, as these categories do not characterise a particular group. The remaining category centroids represent the mean position of respondents who shared this outcome characteristic. In portraying the three offender groups, we first conclude that the largest group of low-rate desisters (group 1) were positioned centrally. This group is generally characterised by positive outcomes such as living in regular accommodation, and not having alcohol and drug abuse problems. However, their profile is not clearly marked, as, for example, the lowrate desisters were characterised by being in an intimate relationship as well as not being in an intimate relationship, and were also associated with unemployment. The low-rate chronic offenders were set apart on the first dimension and characterised by housing problems, alcohol abuse and drug abuse. They were also characterised by having poor contact with their child(ren) and not contributing financially to raising them. High-rate desisters are positioned high on the second dimension, which is associated with being employed, but also with having poor contact with their children and drug abuse. Possibly, holding a job may have contributed to their decline in offending.

Though this combined solution provides us a sketchy profile in terms of multiple adult outcomes of the three largest offender groups in our sample, it should be noted that the profiles were not marked: the category centroids in figure 3 have been placed more centrally than the object scores in figure 2 . This indicates that differences between the groups were gradual and that respondents in the groups may also have shared characteristics. This again shows that while the offending patterns were associated with outcomes in various domains, characteristics such as contact with children are seldom predictive of group membership. 
Table 3. The relationship between background factors, offending patterns, and outcomes in adult life domains

\begin{tabular}{|c|c|c|c|c|c|c|c|c|c|c|c|c|}
\hline & \multicolumn{2}{|c|}{$\begin{array}{l}\text { Accommodation } \\
(\mathrm{N}=248)\end{array}$} & \multicolumn{2}{|c|}{$\begin{array}{l}\text { Employment } \\
(\mathrm{N}=232)\end{array}$} & \multicolumn{2}{|c|}{$\begin{array}{l}\text { Employment } \\
\text { quality }(\mathrm{N}=102)\end{array}$} & \multicolumn{2}{|c|}{$\begin{array}{l}\text { Intimate } \\
\text { relationships } \\
(\mathrm{N}=\mathbf{2 4 6})\end{array}$} & \multicolumn{2}{|c|}{$\begin{array}{l}\text { Parenthood } \\
(\mathrm{N}=\mathbf{2 4 8})\end{array}$} & \multicolumn{2}{|c|}{$\begin{array}{l}\text { Contact with } \\
\text { child(ren) }(\mathrm{N}=163)\end{array}$} \\
\hline & B & SE & B & SE & B & SE & B & SE & B & SE & B & SE \\
\hline Constant & $3.91 * * *$ & 0.85 & 0.52 & 0.55 & $4.29 * * *$ & 0.26 & $1.52^{* *}$ & 0.54 & 0.39 & 0.53 & $2.90 * *$ & 0.96 \\
\hline Gender & 0.15 & 0.56 & -0.09 & 0.37 & -0.05 & 0.17 & -0.27 & 0.36 & $0.94^{*}$ & 0.37 & 0.35 & 0.62 \\
\hline $\begin{array}{l}\text { Problems in the } \\
\text { family of origin }\end{array}$ & 0.10 & 0.19 & -0.15 & 0.14 & 0.09 & 0.07 & -0.04 & 0.12 & -0.01 & 0.13 & -0.07 & 0.20 \\
\hline Victimisation & $-0.64^{*}$ & 0.28 & -0.06 & 0.19 & -0.04 & 0.10 & 0.07 & 0.18 & 0.04 & 0.18 & -0.24 & 0.30 \\
\hline Psychopathology & -0.26 & 0.50 & -0.50 & 0.33 & -0.06 & 0.16 & -0.48 & 0.32 & -0.40 & 0.33 & $-1.05 t$ & 0.61 \\
\hline Aggression & 0.60 & 0.48 & -0.54 & 0.33 & 0.27 & 0.16 & 0.44 & 0.32 & 0.30 & 0.32 & 0.38 & 0.58 \\
\hline $\begin{array}{l}\text { Length of stay in } \\
\text { institution }\end{array}$ & -0.22 & 0.20 & 0.13 & 0.16 & 0.02 & 0.08 & -0.20 & 0.16 & -0.08 & 0.15 & 0.13 & 0.24 \\
\hline $\begin{array}{l}\text { Not completed } \\
\text { education }\end{array}$ & -0.20 & 0.47 & $-1.34 * * *$ & 0.34 & 0.07 & 0.20 & 0.24 & 0.31 & 0.35 & 0.33 & 0.19 & 0.54 \\
\hline $\begin{array}{l}\text { Convicted before } \\
\text { age } 18\end{array}$ & -0.52 & 0.60 & $0.81^{*}$ & 0.34 & -0.26 & 0.18 & $-0.79 *$ & 0.34 & -0.20 & 0.35 & -0.002 & 0.61 \\
\hline $\begin{array}{l}\text { Group 2: high-rate } \\
\text { desisters }\end{array}$ & -0.02 & 0.85 & $0.88+$ & 0.50 & -0.40 & 0.27 & 0.74 & 0.52 & 0.42 & 0.50 & -0.57 & 0.78 \\
\hline $\begin{array}{l}\text { Group 3: low-rate } \\
\text { chronics }\end{array}$ & $-1.17^{*}$ & 0.56 & -0.35 & 0.43 & $-0.91 * * *$ & 0.25 & -0.55 & 0.39 & 0.34 & 0.42 & $-1.95^{* *}$ & 0.66 \\
\hline $\begin{array}{l}\text { Group 4: high-rate } \\
\text { chronics }\end{array}$ & $-2.63 * * *$ & 0.67 & $-1.70^{*}$ & 0.75 & -0.21 & 0.45 & -0.49 & 0.55 & -0.06 & 0.54 & $-1.83^{*}$ & 0.91 \\
\hline $\mathrm{R}^{2}$ & 0.27 & & 0.25 & & 0.22 & & 0.11 & & 0.11 & & 0.21 & \\
\hline
\end{tabular}

$+\mathrm{p}<0.10, * \mathrm{p}<0.05 ; * * \mathrm{p}<0.01 * * * * \mathrm{p}<0.001$

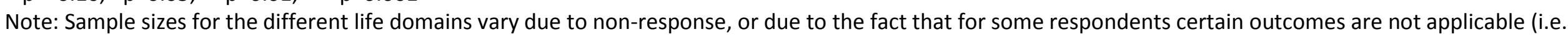
employment quality for the unemployed, contact with children for those who are not parents). 
Table 3. The relationship between background factors, offending patterns, and outcomes in adult life domains (continued)

\begin{tabular}{|c|c|c|c|c|c|c|c|c|c|c|}
\hline & \multicolumn{2}{|c|}{$\begin{array}{l}\text { Financially contributing } \\
\text { to child(ren) }(\mathrm{N}=166)\end{array}$} & \multicolumn{2}{|c|}{$\begin{array}{l}\text { Contact with mental } \\
\text { health services }(N=220)\end{array}$} & \multicolumn{2}{|c|}{ Depression $(\mathrm{N}=225)$} & \multicolumn{2}{|c|}{ Alcohol abuse $(\mathrm{N}=224)$} & \multicolumn{2}{|c|}{ Drug abuse $(\mathrm{N}=222)$} \\
\hline & B & SE & B & SE & B & SE & B & SE & B & SE \\
\hline Constant & $3.48 * * *$ & 0.95 & $-2.24 * * *$ & 0.59 & $-2.88 * * *$ & 0.69 & -0.26 & 0.57 & $-1.90 * *$ & 0.62 \\
\hline Gender & -0.01 & 0.61 & 0.21 & 0.40 & 0.10 & 0.43 & $-0.92 *$ & 0.39 & -0.33 & 0.41 \\
\hline $\begin{array}{l}\text { Problems in the } \\
\text { family of origin }\end{array}$ & -0.04 & 0.19 & $0.25+$ & 0.14 & 0.21 & 0.15 & -0.11 & 0.14 & -0.02 & 0.14 \\
\hline Victimisation & 0.08 & 0.29 & -0.03 & 0.19 & 0.09 & 0.21 & -0.26 & 0.20 & -0.01 & 0.21 \\
\hline Psychopathology & -0.28 & 0.52 & 0.51 & 0.35 & $1.03^{*}$ & 0.42 & 0.13 & 0.34 & -0.04 & 0.37 \\
\hline Aggression & -0.16 & 0.55 & 0.22 & 0.36 & 0.23 & 0.40 & 0.25 & 0.35 & $0.72+$ & 0.39 \\
\hline $\begin{array}{l}\text { Length of stay in } \\
\text { institution }\end{array}$ & $-0.42+$ & 0.25 & 0.08 & 0.16 & 0.19 & 0.18 & 0.05 & 0.16 & 0.08 & 0.17 \\
\hline $\begin{array}{l}\text { Not completed } \\
\text { education }\end{array}$ & -0.46 & 0.50 & $0.89 * *$ & 0.32 & 0.41 & 0.36 & 0.21 & 0.35 & 0.14 & 0.36 \\
\hline $\begin{array}{l}\text { Convicted before } \\
\text { age } 18\end{array}$ & -0.48 & 0.61 & 0.04 & 0.36 & 0.11 & 0.39 & 0.17 & 0.37 & 0.24 & 0.40 \\
\hline $\begin{array}{l}\text { Group 2: high-rate } \\
\text { desisters }\end{array}$ & 0.12 & 0.87 & 0.69 & 0.49 & -0.83 & 0.61 & $-2.08 * *$ & 0.80 & -0.22 & 0.58 \\
\hline $\begin{array}{l}\text { Group 3: low-rate } \\
\text { chronics }\end{array}$ & $-1.36^{*}$ & 0.60 & 0.57 & 0.46 & -0.34 & 0.49 & 0.57 & 0.43 & $1.36^{* *}$ & 0.45 \\
\hline $\begin{array}{l}\text { Group 4: high-rate } \\
\text { chronics }\end{array}$ & $-2.02^{*}$ & 0.82 & $1.28^{*}$ & 0.60 & -0.78 & 0.75 & -0.16 & 0.59 & $1.06+$ & 0.59 \\
\hline $\mathrm{R}^{2}$ & 0.24 & & 0.17 & & 0.12 & & 0.19 & & 0.18 & \\
\hline
\end{tabular}

$+\mathrm{p}<0.10, * \mathrm{p}<0.05 ; * * \mathrm{p}<0.01 ; * * * \mathrm{p}<0.001$ 


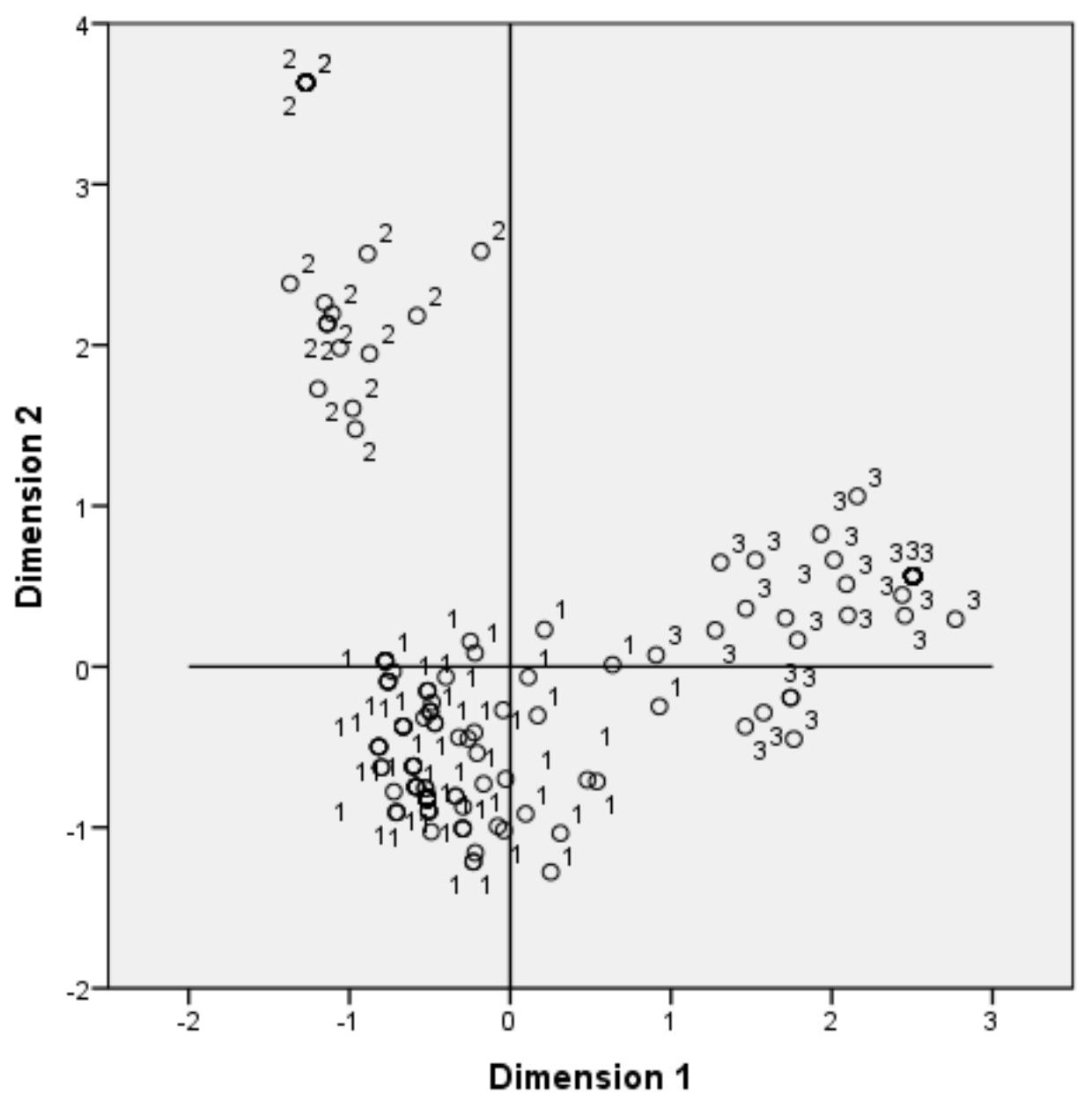

Cases weighted by number of objects.

Figure 2. Object scores by group (1=low-rate desisters, 2=high-rate desisters, 3=low-rate chronics) 


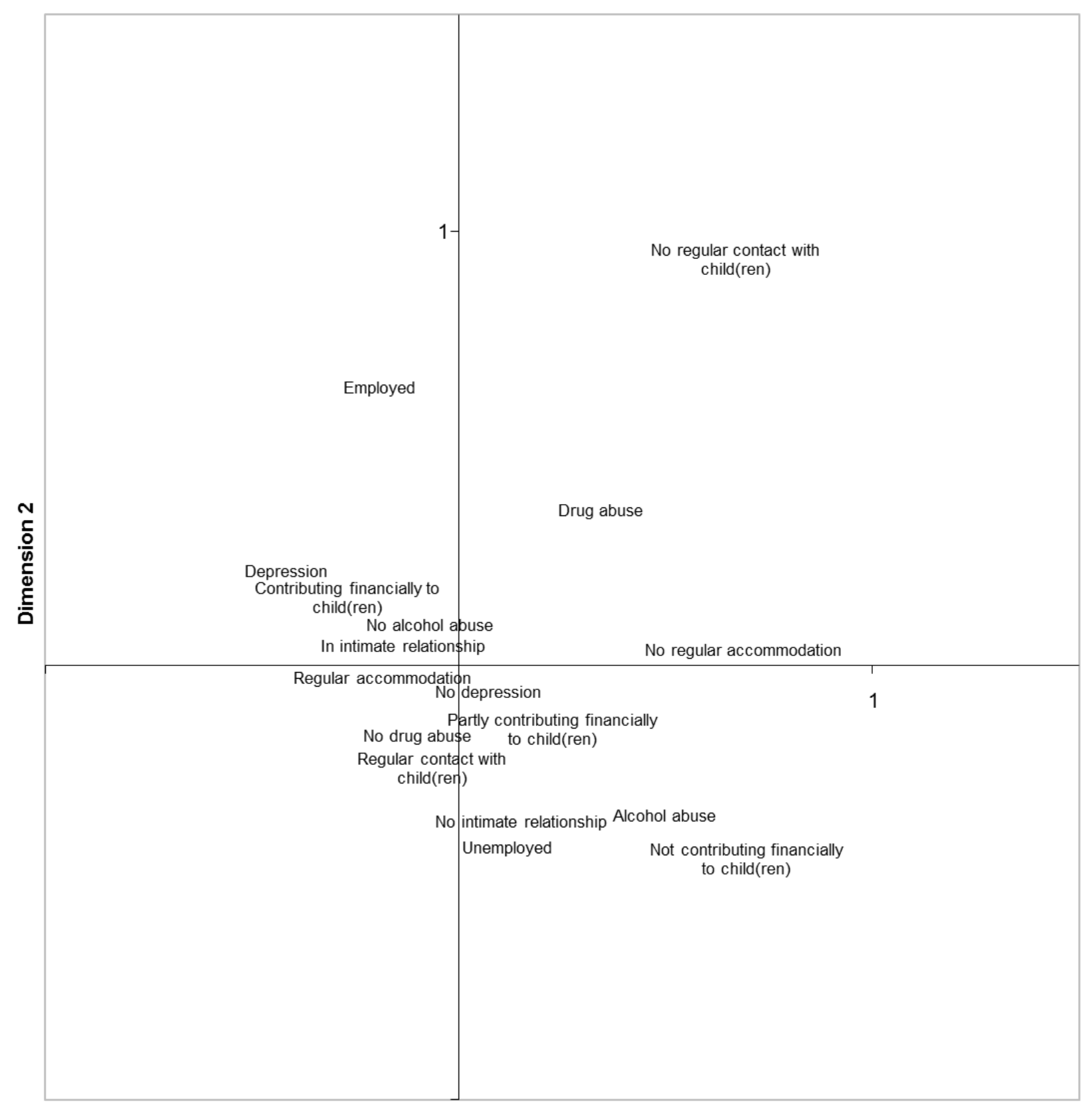

Dimension 1

Figure 3. Projected category centroids 


\section{Discussion}

This study aimed to analyse the association between background characteristics, criminal careers and adult outcomes in a group of men and women who spent time in a judicial treatment institution during adolescence. We examined their outcomes in a variety of conventional adult life domains on average 17 years after they left the institution, using a unique longitudinal dataset from the Netherlands. Our descriptive analyses showed that on average these men and women experienced numerous problems in adulthood: many were unemployed, (mental) health problems were common, and rates of alcohol and drugs abuse were high. This indicates that men and women who spent time in an institution in adolescence due to their problematic behaviour, often go on to live problematic adult lives as well. The findings of this study add to existing research, which is often restricted to following youths for only a short period of time after leaving an institution (e.g. Harder et al., 2011; Ståhlberg et al., 2017), by showing that previously institutionalised youths are at risk of experiencing long-term negative outcomes.

A series of regression analyses were conducted to examine to what extent background factors and offending patterns in adulthood were related to adverse adult outcomes. Taken together, the findings from the regression analyses indicate that in general, those involved in more chronic offending (the low-rate chronic and high-rate chronic offender group) fared worse in adulthood. Both chronic offender groups were more likely to experience difficulties in the domains of accommodation, employment, contact with and financially contributing to their offspring, and drug abuse, and the high-rate offender group was also more likely to seek help for mental health problems.

Interestingly, few of the background factors were significantly related to outcomes in the different life domains. Only a few stand out. Those who experienced childhood victimisation were less likely to live in regular accommodation. Not completing one's education was a clear (and expected) contributor to failure to find employment (e.g. Bernburg \& Krohn, 2003; Heckman, Stixrud \& Urzua, 2006), and was also associated with an increased likelihood of seeking help from professionals for mental health problems. Being convicted prior to age 18 was related to a lower chance of being in an intimate relationship, although adult criminal behaviour was not significantly associated with difficulties in this domain (see also Zoutewelle-Terovan, 2015). Finally, although psychopathology as recorded in the institution was related to depression in adulthood, it was not associated with mental health problems in general; this shows that other (and possibly later) factors may be at play too in the development of adult mental health problems. The lack of significant effects of most background factors may be due to the specific sample under study. All youths were placed in the judicial treatment institution due to their problematic behaviour and often disadvantaged backgrounds, and the differences in terms of their risk profile are only gradual and therefore not very predictive of outcomes in various domains later in life. Also, as respondents participated in the follow-up study on average 17 years after leaving the institution, it is perhaps not surprising that more proximal factors related to involvement in crime rather than distant childhood risk factors were associated with outcomes in adult life domains (see also Laub and Vaillant (2000), who found that proximal behaviours are more predictive of sustained unhealthy lifestyles/premature mortality).

The nonlinear canonical correlation analysis added to the findings from the regression analyses. The results showed that the most serious and chronic offending group did not have a clear profile in terms of the adult outcomes that we included in the analysis. However, our analysis showed that the low-rate chronic offender group was characterised by alcohol abuse, drug abuse and problems in the domain of accommodation. They also were not seeing their children or contributing financially to their upbringing. This group may be cut off from a conventional lifestyle and ties with their relatives through their addiction. Those who had offended at a high rate but subsequently desisted were relatively often employed, which is in line with research on the relationship between employment and crime (Sampson \& Laub, 1993; Verbruggen, Apel, Van der Geest \& Blokland, 2015). The largest group of low-rate desisters appeared to have the most positive outcomes in adulthood. However, the analysis also revealed that the differences between these groups are gradual rather than marked. This is not surprising as many faced difficulties in one or 
more domains. Many had experienced problems finding housing and employment, and many, also those non-criminally involved, had at one point sought 'refuge' in alcohol and (soft) drugs after a childhood that for many felt 'destroyed' (Van der Geest et al., 2013). The results from the nonlinear canonical correlation analysis thus largely support the findings from the different regression analyses, which indicated that chronic offenders fared worse in several life domains than those who managed to desist from offending before or during young adulthood. However, the findings also showed that even low-rate desisters still experience difficulties in adult life domains, such as intimate relationships and employment, even though they are generally better adjusted in adulthood. It underscores the impression that the sample under study is a particularly vulnerable group.

All in all, our analyses showed that over and above their childhood problems, it was to a large extent involvement in criminal behaviour in adulthood that predicted negative outcomes among previously institutionalised youths. The findings are therefore in line with the life course perspective that states that events that happen at different points in the life course could influence the likelihood of positive outcomes in adulthood. Crime and ensuing convictions could lead to adverse outcomes via a process of cumulative disadvantage (Sampson \& Laub, 1997), where initial crime and sanctions can lead to difficulties in conventional domains and therefore weakened social bonds due to labelling processes (e.g. Becker, 1963; Bernburg \& Krohn, 2003; Lopes et al., 2012), which in turn makes further involvement in crime more likely. However, it is also possible that involvement in crime is a marker of underlying problems in people's lives. Based on the current study, the etiological link between childhood problems, adult criminality, and outcomes in a variety of life domains remains unclear. Though childhood problems have the potential to set in motion a criminal development that alters future outcomes, based on our findings it is unclear how these patterns evolve. However, persistent adult offending being a consistent predictor of negative outcomes in adult life, our findings assert that adult offending - as well as the consequences of offending, such as detention - are key to understanding why some individuals entrench into marginal lives.

Taken together, the findings from this study indicate that youths who have spent time in a judicial treatment institution are at risk of experiencing long-term negative outcomes. Therefore, aftercare seems crucial. Support aimed at helping these youths complete education and avoid adult criminal behaviour could help them make successful transitions to conventional adult life domains, so that they can ultimately become healthy, self-sufficient members of society.

Finally, some questions remain unanswered due to limitations of the current study. First, the focus on the specific sample of institutionalised youths, and the lack of a non-institutionalised control group, make it difficult to draw conclusions about the extent to which institutionalisation itself may have contributed to difficulties in conventional life domains. Second, many of the associations we picked up are non-causal: criminal career paths are likely influenced by factors such as mental health and drug abuse, and vice versa. Also, paths are likely intricate with numerous factors accumulating over time towards certain outcomes. Our analyses are in that sense also coarse: we related the state on various domains at one point in time with criminal career development in the years preceding that measurement point. We did not look at the occurrence over the life course of various events, backlashes and advances.

Therefore, several avenues for future research can be outlined. On the one hand, more detailed, longitudinal data on conventional life domains of both institutionalised and non-institutionalised (atrisk) groups, and more advanced longitudinal analyses of life history data would help to shed light on the development in different life domains, and the interactions between events in these life domains, in vulnerable groups. On the other hand, a qualitative, prospective analysis of the lives of young people leaving residential care would be useful in documenting the sequence of positive and negative developments, chance and agency (Giordano, 2017), and the role of background characteristics in the shaping of the lives of these vulnerable men and women. 


\section{References}

Abram, K. M., Zwecker, N. A., Welty, L. J., Hershfield, J. A., Dulcan, M. K., \& Teplin, L. A. (2015). Comorbidity and continuity of psychiatric disorders in youth after detention: A prospective longitudinal study. JAMA Psychiatry, 72(1), 84-93. https://doi.org/10.1001/jamapsychiatry.2014.1375

Aizer, A., \& Doyle, J. J. (2015). Juvenile incarceration, human capital, and future crime: Evidence from randomly assigned judges. The Quarterly Journal of Economics, 130(2), 759-803. https://doi.org/10.1093/qje/qjv003

Allroggen, M., Rau, T., Ohlert, J., \& Fegert, J. M. (2017). Lifetime prevalence and incidence of sexual victimization of adolescents in institutional care. Child Abuse \& Neglect, 66, 23-30. https://doi.org/10.1016/j.chiabu.2017.02.015

American Psychiatric Association (Ed.). (2000). Diagnostic and statistical manual of mental disorders: DSMIV-TR. Washington, DC: American Psychiatric Pub.

Becker, H. (1963). Outsiders: Studies in the sociology of deviance. New York, NY: Free Press.

Bernburg, J. G., \& Krohn, M. D. (2003). Labeling, life chances, and adult crime: The direct and indirect effects of official intervention in adolescence on crime in early adulthood. Criminology, 41, 1287-1318. https://doi.org/10.1111/j.1745-9125.2003.tb01020.x

Boendermaker, L. (1998). Eind Goed, Al Goed? De Leefsituatie van Jongeren Een Jaar na Vertrek uit een Justitiële Jeugdinrichting. Onderzoek en Beleid, No. 167. Den Haag: Wetenschappelijk Onderzoek- en Documentatiecentrum.

Chung, H. L., Little, M., \& Steinberg, L. (2005). The transition to adulthood for adolescents in the juvenile justice system: A developmental perspective. In W. D. Osgood, E. M. Foster, C. Flanagan, \& G. R. Ruth (Eds.), On your own without a net: The transition to adulthood for vulnerable populations (pp. 6891). Chicago, II: University of Chicago Press.

Collins, M. E. (2001). Transition to adulthood for vulnerable youths: A review of research and implications for policy. Social Service Review, 75(2), 271-291. https://doi.org/10.1086/322209

Colins, O., Vermeiren, R., Vreugdenhil, C., van den Brink, W., Doreleijers, T., \& Broekaert, E. (2010). Psychiatric disorders in detained male adolescents: a systematic literature review. The Canadian Journal of Psychiatry, 55(4), 255-263. https://doi.org/10.1177/070674371005500409

Courtney, M. E., \& Dworsky, A. (2006). Early outcomes for young adults transitioning from out-of-home care in the USA. Child \& Family Social Work, 11(3), 209-219. https://doi.org/10.1111/i.13652206.2006.00433.x

Davies, S., \& Tanner, J. (2003). The long arm of the law: Effects of labeling on employment. Sociological Quarterly, 44, 385-404. https://doi.org/10.1111/j.1533-8525.2003.tb00538.x

Farrington, D. P., Coid, J. W., Harnett, L. M., Jolliffe, D., Soteriou, N., Turner, R. E., \& West, D. J. (2006). Criminal careers up to age 50 and life success up to age 48: New findings from the Cambridge study in delinquent development (Home Office Research Study No. 299). London: Home Office.

Fazel, S., Doll, H., \& Långström, N. (2008). Mental disorders among adolescents in juvenile detention and correctional facilities: a systematic review and metaregression analysis of 25 surveys. Journal of the American Academy of Child \& Adolescent Psychiatry, 47(9), 1010-1019. https://doi.org/10.1097/CHI.0b013e31817eecf3

GGD (2005). Dutch Health Monitor. GGD Nederland and Rijksinstituut voor Volksgezondheid en Milieu (RIVM).

Gilman, A. B., Hill, K. G., \& Hawkins, J. D. (2015). When is a youth's debt to society paid? Examining the longterm consequences of juvenile incarceration for adult functioning. Journal of Developmental and Life-Course Criminology, 1(1), 33-47. https://doi.org/10.1007/s40865-015-0002-5

Gifi, A. (1990). Nonlinear multivariate analysis. New York, NY: Wiley.

Giordano, P. (2017). A relational perspective on agency and the desistance process: A reaction to Paternoster and Bachman. In A. Blokland and V. van der Geest (Eds.), The Routledge International Handbook of Life-Course Criminology (pp. 42-49). London: Routledge.

Gottfredson, M. R., \& Hirschi, T. (1990). A General Theory of Crime. Stanford, CA: Stanford University Press. 
Greger, H. K., Myhre, A. K., Lydersen, S., \& Jozefiak, T. (2015). Previous maltreatment and present mental health in a high-risk adolescent population. Child Abuse \& Neglect, 45, 122-134. https://doi.org/10.1016/i.chiabu.2015.05.003

Hamerlynck, S. (2008). Girls in juvenile justice institutions: Psychopathology and sexual risk behavior. Amsterdam: Vrije Universiteit, doctoral dissertation.

Harder, A. T., Knorth, E. J., \& Kalverboer, M. E. (2011). Transition secured? A follow-up study of adolescents who have left secure residential care. Children and Youth Services Review, 33(12), 2482-2488. https://doi.org/10.1016/i.childyouth.2011.08.022

Heckman, J. J., Stixrud, J., \& Urzua, S. (2006). The effects of cognitive and noncognitive abilities on labor market outcomes and social behavior. Journal of Labor Economics, 24(3), 411-482. https://doi.org/10.1086/504455

Lanctôt, N., Cernkovich, S. A., \& Giordano, P. C. (2007). Delinquent behavior, official delinquency, and gender: Consequences for adulthood functioning and well-being. Criminology, 45(1), 131-157. https://doi.org/10.1111/i.1745-9125.2007.00074.x

Laub, J. H., \& Vaillant, G. E. (2000). Delinquency and mortality: A 50-year follow-up study of 1,000 delinquent and nondelinquent boys. American Journal of Psychiatry, 157(1), 96-102. https://doi.org/10.1176/ajp.157.1.96

Lopes, G., Krohn, M. D., Lizotte, A. J., Schmidt, N. M., Vásquez, B. E., \& Bernburg, J. G. (2012). Labeling and cumulative disadvantage: The impact of formal police intervention on life chances and crime during emerging adulthood. Crime \& Delinquency, 58(3), 456-488. https://doi.org/10.1177/0011128712436414

Moffitt, T. E., Caspi, A., Harrington, H., \& Milne, B. J. (2002). Males on the life-course-persistent and adolescence-limited antisocial pathways: Follow-up at age 26 years. Development and Psychopathology, 14(1), 179-207. https://doi.org/10.1017/S0954579402001104

Nagin, D. S. (1999). Analyzing developmental trajectories: A semiparametric, group-based approach. Psychological Methods, 4(2), 139-157. https://doi.org/10.1037/1082-989X.4.2.139

Nagin, D. S. (2005). Group-Based Modeling of Development. Cambridge, MA: Harvard University Press. https://doi.org/10.4159/9780674041318

Nilsson, A., \& Estrada, F. (2009). Criminality and life-chances. A longitudinal study of crime, childhood circumstances and living conditions up to age 48. Department of Criminology Report Series, Report 2009:3.

Osgood, D. W., Foster, E. M., Flanagan, C., \& Ruth, G. R. (2005). On your own without a net: The transition to adulthood for vulnerable populations. Chicago, Il: University of Chicago Press. https://doi.org/10.7208/chicago/9780226637853.001.0001

Piquero, A. R., Daigle, L. E., Gibson, C., Piquero, N. L., \& Tibbetts, S. G. (2007). Research note: Are life-coursepersistent offenders at risk for adverse health outcomes? Journal of Research in Crime and Delinquency, 44(2), 185-207. https://doi.org/10.1177/0022427806297739

Piquero, A. R., Farrington, D. P., Nagin, D. S., \& Moffitt, T. E. (2010). Trajectories of offending and their relation to life failure in late middle age: Findings from the Cambridge study in delinquent development. Journal of Research in Crime and Delinquency, 47(2), 151-173. https://doi.org/10.1177/0022427809357713

Radloff, L. S. (1977). The CES-D scale: A self-report depression scale for research in the general population. Applied Psychological Measurement, 1, 385-401. https://doi.org/10.1177/014662167700100306

Sampson, R. J., \& Laub, J. H. (1993). Crime in the making: Pathways and turning points through life. Cambridge, MA: Harvard University Press.

Sampson, R. J., \& Laub, J. H. (1997). A life-course theory of cumulative disadvantage and the stability of delinquency. In T. P. Thornberry (Ed.), Developmental theories of crime and delinquency (pp. 1-29). New Brunswick, NJ: Transaction. 
Ståhlberg, O., Boman, S., Robertsson, C., Kerekes, N., Anckarsäter, H., \& Nilsson, T. (2017). A 3-year follow-up study of Swedish youths committed to juvenile institutions: Frequent occurrence of criminality and health care use regardless of drug abuse. International Journal of Law and Psychiatry, 50, 52-60. https://doi.org/10.1016/j.ijlp.2016.09.004

Tarren-Sweeney, M. (2008). The mental health of children in out-of-home care. Current Opinion in Psychiatry, 21(4), 345-349. https://doi.org/10.1097/YCO.0b013e32830321fa

Van der Burg, E., de Leeuw, J., \& Verdegaal, R. (1988). Homogeneity analysis with k sets of variables: An alternating least squares method with optimal scaling features. Psychometrika, 53(2), 177-197. https://doi.org/10.1007/BF02294131

Van der Geest, V. R. (2011). Working their Way into Adulthood. Delinquency and Employment in High-Risk Boys to Age 32. VU University Amsterdam, doctoral dissertation.

Van der Geest, V., Bijleveld C., \& Verbruggen, J. (2013). Vallen en opstaan. Mannen en vrouwen 17 jaar na vertrek uit een justitiële jeugdinrichting. Amsterdam: Vrije Universiteit en Nederlands Studiecentrum Criminaliteit en Rechtshandhaving.

Van der Molen, E., Vermeiren, R. R. J. M., Krabbendam, A. A., Beekman, A. T. F., Doreleijers, T. A. H., \& Jansen, L. M. C. (2013). Detained adolescent females' multiple mental health and adjustment problem outcomes in young adulthood. Journal of Child Psychology and Psychiatry, 54(9), 950-957. https://doi.org/10.1111/icpp.12044

Van Vugt, E., Lanctôt, N., Paquette, G., Collin-Vézina, D., \& Lemieux, A. (2014). Girls in residential care: From child maltreatment to trauma-related symptoms in emerging adulthood. Child Abuse \& Neglect, 38(1), 114-122. https://doi.org/10.1016/j.chiabu.2013.10.015

Verbruggen, J. (2014). Previously institutionalized youths on the road to adulthood. VU University Amsterdam, doctoral dissertation.

Verbruggen, J., Apel, R., Van der Geest, V., \& Blokland, A. (2015). Work, income support and crime in the Dutch welfare state. A longitudinal study following vulnerable youths into adulthood. Criminology, 53(4), 545-570. https://doi.org/10.1111/1745-9125.12080

Verbruggen, J., Van der Geest, V., \& Blokland, A. (2016). Adult life adjustment of vulnerable youths. The relationship between criminal history, employment history and adult life outcomes. Journal of Developmental and Life-Course Criminology, 2(4), 466-493. https://doi.org/10.1007/s40865-016$\underline{0040-7}$

Vinnerljung, B., \& Sallnäs, M. (2008). Into adulthood: a follow-up study of 718 young people who were placed in out-of-home care during their teens. Child \& Family Social Work, 13(2), 144-155. https://doi.org/10.1111/j.1365-2206.2007.00527.x

Wartna, B. S. J., El Harbachi, S., \& Van der Laan, A. M. (2005). Jong vast: een cijfermatig overzicht van de strafrechtelijke recidive van ex-pupillen van justitiële jeugdinrichtingen. Den Haag: Wetenschappelijk Onderzoek- en Documentatiecentrum.

Welty, L. J., Harrison, A. J., Abram, K. M., Olson, N. D., Aaby, D. A., McCoy, K. P., Washburn, J. J., \& Teplin, L. A. (2016). Health disparities in drug-and alcohol-use disorders: a 12-year longitudinal study of youths after detention. American Journal of Public Health, 106(5), 872-880. https://doi.org/10.2105/AJPH.2015.303032

Zoutewelle-Terovan, M. (2015). Criminality and family formation. VU University Amsterdam, doctoral dissertation. 


\section{Endnotes}

1. Formal consent for the study was obtained from the Netherlands Ministry of Security and Justice, and the Ethics Committee of the Faculty of Law of VU University approved the study and its procedures.

2. The variable 'contact with other health services' mainly represents contact with health services due to physical health problems. However, it is possible that respondents had contact with a company doctor or went to $A$ \& E for problems related to mental health.

3. One meets the criteria for alcohol abuse / substance abuse when he or she shows a maladaptive pattern of drinking/substance use, manifested by for example recurrent alcohol-related / substancerelated legal problems, or recurrent use of alcohol / substance use resulting in a failure to fulfill major role obligations at work, school, or home (American Psychiatric Association, 2000: 199; 214).

4. We used OVERALS, which is an extension of nonlinear canonical correlation analysis that is implemented in SPSS (Van de Burg, de Leeuw and Verdegaal, 1988). This technique uses rescaling of the categories of any noninterval variable by using optimal scaling.

5. For detailed information on gender differences in background characteristics, see Verbruggen et al. (2016). 